\title{
Lo real y lo fantástico en los cuentos de Sauce ciego, mujer dormida de Murakami.
}

\section{The realistic and the fantastic material in Murakami's stories Sauce ciego, mujer dormida.}

\author{
Heraclia Castellón Alcalá \\ Catedrática de Lengua y Literatura / Universidad Nacional de Educación a Distancia (Almería). \\ (ESPAÑA) \\ CE: $\underline{\text { heracliacastellon@gmail.com ID ORCID: 0000-0001-8303-9426 }}$
}

DOI: $10.32870 /$ sincronia.axxiii.n76.27b19

Esta obra está bajo una Licencia Creative Commons Atribución-NoComercial 4.0 Internacional

Recibido: $29 / 03 / 2019$

Revisado: 20/05/2019

Aprobado: $11 / 06 / 2019$

\section{RESUMEN}

La producción narrativa de Murakami se deslinda en novelas y en obras de menor formato, los cuentos o relatos breves. Es de interés comprobar si en una obra con señas tan particulares ambos subgéneros muestran las mismas coordenadas de autor. Este trabajo analiza dos marcas intrínsecas de este escritor, el realismo de los relatos y, al mismo tiempo, el recurso al componente fantástico en los cuentos del libro Sauce ciego, mujer dormida. La coexistencia paradójica de ambos rasgos merece especial atención. Este trabajo se acerca a comprobar el peso de cada una de estas fuerzas en este conjunto de relatos, para detenerse en algunos más polarizados hacia una de los dos.

Palabras clave: Narrativa contemporánea. Literatura japonesa. Cuentos 


\begin{abstract}
:
The narrative production of Murakami is defined in novels and works of smaller format, short stories. It is of interest to verify if in a work with so particular signs both types of narrative genders show the same coordinates of author. This work analyzes two intrinsic marks of this writer, the realism of the stories and, at the same time, there course to the fantastic component in the stories of the book Blind Willow, Sleeping Woman. The paradoxical coexistence of both features deserves special attention. This work is about checking the weigh to feach of these forces in this set of stories, to stop in some more polarized towards one of the two.
\end{abstract}

Keywords: Contemporary narrative. Japanese literature. Short stories

\title{
Introducción
}

La creación de historias del escritor Haruki Murakami ha ido avanzando en dos direcciones con parejo acierto; sus novelas lo identifican por la idiosincrasia de su mundo propio, y sus cuentos alcanzan igualmente el brillo particular de sus piezas más extensas. El volumen Sauce ciego, mujer dormida acoge veinticuatro relatos breves de elevada fuerza narrativa y atrayente forma; en él se albergan cuentos cuya tipología es diversa y contrastada, si bien, de alguna u otra forma, permiten constatar en su materia constituyente la presencia de dos elementos nucleares en la literatura murakamiana: por una parte, el registro cuidadoso de escenarios, entornos y rasgos afectivos atribuibles a lo real y existente, mientras que, por otro lado, irrumpe en algunas tramas la presencia de lo fantástico, de otra realidad más allá de la conocida y delimitada convencionalmente. Sobre ese haz de fuerzas se sostienen muchos de los relatos de este libro, de ahí que interese atender a su aparición y tomar nota de su entidad y dimensiones en cada caso.

En el prólogo del libro Sauce ciego, mujer dormida, el propio Murakami da indicaciones tanto acerca de la fijación cronológica de los cuentos, como acerca de su respectiva aparición editorial y de su propio vínculo y consideración hacia ellos como autor; gracias a este útil y valioso proemio se nos aclara que la escritura de cuentos a él le resulta estimulante a la vez que incompleta, menor, en comparación con las novelas, género que cree le cuadra mejor. Los cuentos son más versátiles, 
demandan menos esfuerzo, por lo que su disposición hacia ellos es la de quien se entrega a un divertimento, algo grato, de lo que quizás pueda surgir otro fruto más enjundioso, quizás un primer paso hacia una ulterior novela, cuya redacción Murakami gusta rotar alternativamente con la de los cuentos, nunca simultanear. Sabemos por él mismo, pues, que esta compilación contiene algunos de sus primeros cuentos, en concreto dos de los tres primeros, La tía pobre y La tragedia de la mina de carbón de Nueva York. Junto a estos dos figuran otros también forjados en su primera etapa de narrador, en los primeros ochenta, de 1981 a 1982, El espejo, Un día perfecto para los canguros, Somorgujo, El año de los espaguetis y Conitos. De más adelante, de la década de los noventa, proceden algunos otros cuentos de este libro: La chica del cumpleaños, Los gatos antropófagos, EI séptimo hombre y El hombre de hielo. Los cuentos de fecha más reciente del volumen serían cinco que aparecieron en Japón con el título de Cuentos extraños de Tokio: Viajero por azar, Hanaley Bay, En cualquier lugar donde parezca que esto pueda hallarse, La piedra con forma de riñón que se desplaza y El mono de Shinagawa. Por otro lado, hay cuentos que han experimentado una relaboración desde su primera publicación (Cangrejo, La tía pobre, El cuchillo de caza y Sauce ciego, mujer dormida). Para este trabajo, se parte de la versión electrónica de la edición de Tusquets, tan admirablemente traducida por Lourdes Porta; de la versión electrónica procede, en concreto, la cita de páginas.

La fusión de elementos contrapuestos dentro de los mismos cuentos es destacada en la nota de presentación de la propia editorial Tusquets, tal como se reseña en la tapa:

Haruki Murakami mezcla con calculada ambigüedad el sueño y la vigilia, introduce elementos fantásticos y oníricos, se sirve de referentes como el jazz o permite que los cuervos hablen, pero, sobre todo, crea personajes inolvidables, enfrentados al dolor o al amor, o vulnerables y necesitados de afecto. Murakami en estado puro (Murakami, 2008).

Y en general, su obra es así entendida y valorada:

Haruki Murakami logra, a través de una prosa sencilla y melódica, exponer los problemas sociales más relevantes en la actualidad, llevando a los lectores hacia pasajes surrealistas 
llenos de secretos y colmarlos de emociones profundas tales como el amor y la soledad (Echeverri, 2015, p.101).

Entre los veinticuatro relatos de esta colección hay heterogeneidad temática, constructiva y estilística. Y también diferencias de extensión: algunos cuentos son extremadamente breves (El año de los espaguetis, El espejo, La chica del cumpleaños, Un día perfecto para los canguros, Somorgujo), en tanto que otros revisten mayor desarrollo y vuelo narrativo (Tony Takitany, El mono de Shinagawa, El folclore de nuestra generación: prehistoria del estadio avanzado del capitalismo). Estos últimos tejen una trama por secuencias diferenciadas, a partir de los personajes centrales, bien definidos, y construyen procesos de acciones que se prolongan en franjas temporales, para las que se dispone un final. Los primeros, en cambio, son intensos fogonazos, casi instantáneos, escenas aisladas más que secuencias sucesivas; es en ellos donde más priva el fragmentarismo menos apegado al orden lógico y a la verosimilitud de los hechos, más proclives a llegar a las cotas del absurdo y el surrealismo. En ellos es notoriamente aplicable lo que Sotelo ha subrayado de la ficción de Murakami, su atracción por lo inesperado: "Las evoluciones de las tramas suelen ser imprevisibles, alejadas de la conexión con la vida o con la propia realidad” (Sotelo, 2013, p.315).

Como constante en las historias noveladas de Murakami, tanto en novelas como en cuentos, los protagonistas arquetípicos están caracterizados por el rasgo de la soledad, el desamor, una cierta desorientación en su rumbo vital: "Los personajes suelen ser sujetos solitarios, raros, obsesivos, enfermos, 'hombres sin atributos', que observan la vida desde la distancia de su soledad y marginalidad, quizá porque no entienden el mundo que les ha tocado vivir" (Sotelo, 2013, p.314). Al ser este un denominador común en la composición de personajes del novelista japonés, ha sido subrayado en numerosas interpretaciones; la siguiente de Cubillo Paniagua se basa específicamente en el libro Sauce ciego, mujer dormida:

Existen tres elementos, la soledad, el silencio y la oscuridad, que resultan recurrentes en el cuentario de Murakami y que son señalados por Freud como los factores en torno a los que se anudó la angustia infantil en los sujetos, asunto no resuelto en la mayoría de seres 
humanos. El cuento titulado 'El año de los espaguetis' desarrolla notablemente los temas de la soledad y el silencio, aunque muchos otros relatos de Murakami (como por ejemplo 'Náusea, 1979' y 'El hombre de hielo') dan cuenta de ellos; de hecho, la mayor parte de los personajes de estos cuentos son individuos sumamente solitarios y silenciosos, quienes tratan de resolver sus miedos internos en soledad (2011, p.26).

El acercamiento a estos cuentos permite comprobar la presencia en los relatos como vectores determinantes de, por una parte, la captación de la realidad dada y, por otra, la fuga de la trama hacia el elemento fantástico, ajeno a la pura realidad física y a su mera comprensión lógica. Esta dualidad ha sido analizada, mayoritariamente en las novelas, por profundos conocedores de la obra de Murakami (Rubio, Sotelo...); dada esta confluencia de contenidos, a Murakami se le integra en un realismo fantástico (Sotelo, 2013, p. 41). Los cuentos de Sauce ciego, mujer dormida atesoran ambas fuerzas con la misma fluidez y gallardía que las novelas, sus hermanas mayores. Ilustran con pleno acierto lo que se asocia a la marca de la pluma murakamiana:

En Murakami se observa una tensión permanente entre la realidad y la ficción. Su estética posee una base sensorial que, a veces, prescinde de soluciones racionales. Sus historia son posibles, aunque no sucedan realmente, como mundos posibles que se expresan a través de la literatura. [... ] Sus objetos, personas, acciones e ideas son semejantes a la realidad, pero también hay otros que no imitan ese modelo, y son maravillosos e imposibles a la vez que verosímiles y convincentes (Sotelo, 2013, p.41).

Otra consideración coincidente es la de Echeverri:

Su literatura podría entrar en el círculo de Gabriel García Márquez y Cortázar donde el surrealismo parece cohabitar junto con la realidad. Leer a Murakami significa adentrarse en un mundo de libros, jazz y música clásica, donde los personajes -usualmente solitarios- se encuentran en una situación de 'distorsión' de su realidad en el cual conocen personas del mundo onírico, del mundo real y a un inusual personaje que puede «saltar» entre los dos mundos (2015, p.103). 


\section{El realismo en los cuentos de Sauce ciego, mujer dormida}

La ficción de Murakami se asienta, en general,sobre un marco humano, espacio-temporal y psicológico que el autor compone, con señalados perfiles verosímiles que fijan las historias de muchos de estos cuentos. En ellos, los personajes están descritos con trazos que los hacen reconocibles como miembros de una galería de tipos humanos, de hombres y mujeres, cuya peripecia biográfica se nos detalla, a veces de forma minuciosa. Conocemos su trayectoria, su infancia, su casi siempre doloroso paso por la adolescencia y juventud; se nos proporcionan datos acerca de su aspecto, indumentaria, su ocupación y destino profesional, sus aficiones y, en buen número de cuentos, sus sentimientos: añoranzas, frustraciones, desconcierto, soledad, miedos...La autorizada voz del profesor Rubio (2012) sintetiza los cuentos de este libro como una

Extraña antología del vacío, la pérdida y el silencio. [...] El vacío y la nada. Las espadas de la cultura japonesa. Forjadas en la fragua de desapariciones y pérdidas, los japoneses las llevan enfundadas en la vaina de blancos silencios. En Murakami las tres nociones -péddida, silencio y vacío- forman un océano hueco de significados. Y el silencio de los interrogantes resuena tanto que hasta los gatos se van (p.188-189).

La radiografía de los personajes alcanza a ocuparse de sus preferencias gastronómicas, de bebidas, y, por supuesto, musicales; poco escapa a la exhaustiva mirada que ahonda en el tipo humano y en su bagaje y entorno. Uno de los profundos conocedores de la obra murakamiana, Justo Sotelo (2013, p.57), ha señalado cómo sus ficciones parecen mostrarnos las vidas de seres de naturaleza humana real, de personas de vida común:

La primera sensación que se recibe cuando se abre una novela de Murakami es que el autor va a referirse a personas normales y corrientes, y hablar de las pequeñas cosas que les ocurren cada día, generalmente a través de los ojos de un narrador en primera persona.

En la misma dirección apunta la afirmación de Cubillo:

Murakami aparentemente se sitúa en el terreno de la realidad cotidiana (de hecho constantemente aporta criterios de verosimilitud para que el lector se convenza de que el 
hecho narrado en efecto ocurrió), de modo que acepta las condiciones para el surgimiento del sentimiento ominoso que resultan válidas en la vida cotidiana (2011, p.27).

Uno de los cuentos que rebosa información de enorme utilidad histórica, sociológica, es El folclore de nuestra generación: prehistoria del estadio avanzado del capitalismo. En este texto hace un balance desencantado y dolorido de la etapa de juventud de su generación. Habla Haruki Murakami -como miembro de su generación-de su época universitaria, convulsa y agitada, desde la atalaya de la madurez, dos décadas después, rondando ya los cuarenta. Vierte en el inicio del texto ciertas reflexiones sociológicas sobre el espíritu de época, y deja oír su autocrítica por no haber aprendido y reconocido lo que la época significó, por haberse limitado solo a vivirla sin cerrar las fracturas psicológicas que se abrieron. Con este apartado expositivo inicial, previo a la ficción, de El folclore de nuestra generación..., casi se puede considerar que el texto no se va a consistir en un relato, sino más bien en un artículo periodístico de corte ensayístico, memorialista, con un arranque puramente autobiográfico: “Nací en el año 1949. En 1961 empecé la enseñanza media y, en 1967, entré en la universidad. En este sentido, creo que se me puede considerar un típico hijo de los años sesenta" (Murakami, 2008, p.58).

Y vive la turbulencia de ese momento:

Pasé el periodo más vulnerable, más inmaduro y a la vez más decisivo de mi vida respirando a pleno pulmón el aire salvaje, improvisado y espontáneo de los años sesenta, que, como es lógico, acabó emborrachándome por completo. ¡Había tantas puertas que debíamos abrir de una patada! Sí. ¡Y qué fantástico es tener ante los ojos puertas para que las abriéramos a puntapiés! (Murakami 2008, p.58).

Era el momento en que su generación devanaba sus acciones y protestas con la banda sonora de la legendaria música de esa década: "Y todo eso con los Doors, los Beatles, Bob Dylan y los otros como música de fondo" (Murakami, 2008, p.58). 
La califica de época excepcional, en ella se mezclaron "el heroísmo y la villanía, la embriaguez y el desengaño, el martirio y el arribismo, la generalización y la concreción, el silencio y la elocuencia" (p.59).Desde su proximidad a los cuarenta, vierte su autocrítica generacional: vivieron intensamente, pero no supieron aprender de esa experiencia, ni reflexionaron acerca de lo que suponía lo que vivieron y lo que dejaron atrás. En El folclore de nuestra generación, como en otro cuento posterior del libro Hombres sin mujeres, Yesterday, se lamenta el narrador, trasunto de Murakami, de cómo sus vidas están marcadas -vale decir frustradas- por sus actitudes juveniles, en especial en lo que atañe a las relaciones amorosas. Así lo ha subrayado Sotelo:

Murakami reflejó los miedos e inseguridades de los jóvenes de los años ochenta ante su propio cuerpo y las primeras experiencias sexuales. En ciertas épocas, Japón ha sido un país cerrado al exterior, y algunos elementos de su organización social y cultural se han resquebrajado tras la derrota de la Segunda Guerra Mundial. Las novelas de Murakami han sabido reflejar ese movimiento de la sociedad japonesa de apertura al exterior, pro también de reflujo sobre sí misma. Sus personajes son dominados por los miedos y temores más profundos, y por eso se abren hacia los demás, hacia la cultura y la sociedad occidental, pero sin olvidar sus raíces (2013, p.319).

Ese eco apesadumbrado de un periodo juvenil de especial huella desalentada lo advierte muy certaramente Rubio, para quien Murakami, por su peripecia generacional, podría ser considerado como el "escritor del Zenkyoto" (Rubio, 2012, p.97), un movimiento universitario de protesta en el Japón de los años 60, "expresión colectiva de la insatisfacción sentida por una juventud con el modelo de rápido desarrollo económico y ajustes sociales experimentados en aquella época" (p.87), un movimiento contracultural y de clamor por las libertades individuales que ejerció, según Rubio, profunda influencia espiritual en Murakami (p. 95).

En cuanto al modo de novelar, al igual que en la narrativa tradicional, Murakami cuida la entidad de los personajes, su identidad física y psicológica; esta, muy especialmente. Pero es preciso y puntilloso en las descripciones físicas; este fragmento del cuento Sauce ciego, mujer dormida, el primero de ese libro, así lo atestigua: 
Mi primo se sentó dándome la espalda y encaró hacia mí la oreja derecha. Tenía la oreja muy bien formada. En sí, era de pequeño tamaño, pero la carne del lóbulo aparecía abultada como una magdalena recién horneada. Se trataba de la primera vez que le inspeccionaba la oreja a alguien. Observándola con atención pude constatar que, en comparación con otros órganos del cuerpo humano, la oreja es, desde el punto de vista morfológico, un gran enigma. Presenta, en algunos puntos, pliegues y vueltas hasta lo irrazonable, en otros, protuberancias y depresiones. Posiblemente haya ido adoptando esta curiosa forma en el transcurso de la evolución con el objeto de captar mejor los sonidos, y retenerlos. Rodeado de paredes deformes, parece un único agujero negro que se abre como si fuera la entrada de una gruta misteriosa (Murakami, 2008, p.20).

Su mirada escrutadora se posa con el mismo tino no ya sobre los protagonistas, sino incluso sobre personajes apenas mencionados, sin relieve alguno en la acción, como vemos con la descripción de la cajera del restaurante donde trabaja la protagonista de La chica del cumpleaños:

Además había un encargado. Y una mujer delgada de mediana edad que se sentaba tras la caja registradora. Se decía que la mujer llevaba en el mismo sitio desde la inauguración del local. Apenas se alzaba de su asiento, como la patética abuela de La pequeña Dorrit de Dickens. Cobraba y se ponía al teléfono. No tenía otra función. No abría la boca si no era estrictamente necesario. Siempre vestía de negro. Su apariencia era dura, fría y, de estar flotando en el mar de noche, el barco que hubiese chocado con ella seguro que se habría hundido (Murakami, 2008, p.23).

Concisión, destreza, referencias literarias y hallazgo metafórico, todo en un personaje intrascendente y plano.

Es esclarecedor conocer cómo Murakami se plantea el dibujo de sus personajes:

Los personajes son elementos esenciales para la novela. No hace falta insistir en ello. Un escritor debe crear personajes que parezcan reales y, además deben resultar interesantes, atractivos, autónomos. Hay que dejarles actuar por cuenta propia hasta cierto punto. 
Después hay que colocarlos en el centro de la narración a al menos cerca de ahí (Murakami, 2017, p.229).

El mismo esmero se aplica en la creación o evocación de los paisajes, sean naturales o urbanos:

En el extremo de la playa se extendían, como un pan ácimo partido por la mitad, las dentadas rocas del acantilado a donde iban a morir, a intervalos regulares, unas pequeñas olas. Unas olas tan graciosas y ordenadas como medidas con regla (El cuchillo de caza, Murakami, 2008, p.86).

Están también recogidos en estas páginas, además de los escenarios cotidianos y conocidos, los lugares y elementos de paisaje real donde se cierne una tragedia, como esta descripción de las pavorosas olas de un tifón en la costa japonesa:

En aquel instante, una gigantesca ola se erguía hacia lo alto como una enorme serpiente y se disponía a atacar. Era la primera vez en mi vida que veía una ola tan horrenda. Era tan alta como un edificio de tres plantas. $Y$, sin un sonido (al menos yo no recuerdo que lo hubiera y en mi memoria siempre avanza en silencio), se alzó a las espaldas de K, tan alta que tapaba el cielo. [...] Con estruendo, dividida en innumerables brazos, la ola rompió de forma salvaje contra la arena y un mar de salpicaduras voló por los aires, como producto de una explosión (El séptimo hombre, Murakami, 2008, p.151).

Dentro de esta galería de cuentos, aparece algún protagonista afectado por una circunstancia biográfica repetida en los relatos murakamianos: el hombre abandonado por su mujer; aquí quien sufre tal abandono es el protagonista de Los gatos antropófagos, cuya consciencia se tambalea cuando eso sucede; o también el protagonista del cuento Tony Takitani, cuya soledad se interrumpió al enamorarse de su esposa, la cual muere pronto, como también su padre, cuyos discos hereda y vende: "Cuando aquel montón de discos desapareció, Tony Takitani se quedó, entonces sí, completamente solo" (p.177). El rasgo recurrente de la soledad en los personajes murakamianos aquí cabrá ilustrarlo, entre otros, con cuentos como El año de los espagueti, cuyo 
protagonista refiere que en 1971 se auto recluyó, dedicándose intensa y compulsivamente a cocinar de mil maneras posibles los espaguetis; cuando una llamada irrumpe en su retiro -la exnovia de un amigo desaparecido le pide ayuda para localizarlo, ya que necesita urgentemente un dinero que ella le había prestado-,la atiende displicente, y se excusa por tener que ocuparse de sus espagetis al fuego; el final del cuento esculpe la asociación que aquí se establece espaguetis / soledad: "Los italianos se habrían quedado estupefactos si hubieran sabido que lo que exportaban en 1971 no era más que soledad" (p.163). Acerca de esta rúbrica de personajes solitarios en los relatos de Murakami se han formulado múltiples observaciones, y también alguna en particular en torno a este cuento:

Esta evidente deshumanización y este deseo de aislamiento del hombre de los espaguetis podrían obedecer, según el planteamiento de Freud, a una angustia infantil no resuelta anudada en torno a la soledad, el silencio y la oscuridad, lo cual en muchas ocasiones conduce a los individuos a situaciones que pueden ser calificadas como ominosas, pues le vuelven ajeno y extraño aquello que en principio resulta ser lo más familiar: el ser humano mismo (Cubillo, 2011, p.27).

Pero por ser menos frecuente el final en positivo, abierto a la esperanza de la salvación, llama la atención El séptimo hombre, cuyo protagonista innominado -solo es mencionado por el orden en que toma la palabra en no se sabe qué reunión- relata cómo desde la infancia ha sido atormentado por un atroz sentimiento de culpa, al asumir su incapacidad / cobardía para avisar a su amigo, desprevenido en la playa, de la monstruosa ola del tifón que fatalmente lo arrastró; esa pasividad le ha arruinado su vida: aquejado de terrores, pesadillas, ha vivido presa del remordimiento. Pero felizmente, y en la misma playa, un día se siente liberado, aligerado de ese torturador fardo:

A partir de entonces no he tenido más sueños espantosos. No he vuelto a despertarme con un alarido en plena noche. Ahora me dispongo a iniciar una nueva vida. No. Tal vez sea demasiado tarde para ello. Tal vez sea muy poco el tiempo que me queda en el futuro. Pero, aunque así sea, me siento agradecido por haber sido salvado, al final, de ese modo, por haber experimentado una recuperación. Sí. Porque yo tenía muchas posibilidades de acabar 
mi vida sin haber recibido la salvación, alzando un triste lamento dentro de las tinieblas del pánico (p.158).

\section{Lo fantástico en algunos cuentos de Sauce ciego, mujer dormida}

En buena parte de los cuentos del libro Sauce ciego, mujer dormida, al igual que en la mayoría de sus novelas, hace su entrada el elemento fantástico, que escapa a una explicación racional y fehaciente, y su aparición suele dar un giro en la acción, mueve en algún sentido la trama. A otra escala, también se comprueba que Murakami recurre a términos metafóricos y expresiones simbólicas para referirse o explicar aspectos de la realidad que están presentes en ella, pero que proceden o intervienen desde otro plano, desde otra dimensión. Ambos procedimientos creativos uno más estructural, en la sustancia del relato, y el otro más externo, en la forma del texto- pueden ser declarados como piezas clave que configuran la literatura del escritor. Preguntado recientemente sobre su proclividad hacia lo inexplicable, corroboraba en una entrevista su tendencia hacia lo que se podría considerar extraño:

La vida es misteriosa y quizá ciertas cosas que cuento resulten extrañas para otros, pero son naturales para mí. Que un espíritu tome la forma de la figura de un cuadro o que haya personajes cuyas sombras se desdoblen son ideas habituales en mi vida, metafóricamente hablando. Como narrador pienso a nivel del relato; todo puede pasar. Los niños lo viven con más sencillez. Cuando eres niño y en un libro alguien atraviesa la pared, es natural. Los adultos dicen: 'Es extraño'. Soy casi un viejo, pero todavía creo que puedes atravesar la pared y espero que el lector también lo crea (R. Garzón, entrevista EL PAÍS, 1 Febrero 2019).

Queda, pues, así proclamada la disposición de Murakami a que se integren en las tramas hechos que desde una perspectiva racional no se producen en el mundo natural, de mera entidad física. Dentro de este libro abundan los ejemplos; se puede acudir, entre otros, a La chica del cumpleaños o a La tía pobre. En el primero, a una joven camarera el dueño del restaurante donde trabaja, a quien ve por primera vez, le dice -al saber que es su cumpleaños- que pida un deseo, y oficia un brevísimo ritual, tras el cual le asegura ya lo ha conseguido; sin ninguna otra aparición fantástica, el 
relato contiene un elemento irreal, la magia de los deseos cumplidos. En La tía pobre, uno de los primeros cuentos escritos por Murakami, aparece ya una de las señas familiares a sus relatos: la conciencia de la identidad propia en sus distintas formas; el protagonista, un joven que escribe, piensa con afecto en la figura de las tías pobres, quiere escribir algo sobre ellas y, desde ese momento, descubre que porta una tía pobre adherida a su espalda, o más bien un ser etéreo cambiante: "Llegué a la conclusión de que lo que llevaba pegado detrás no era una tía pobre con una forma definida, sino una especie de ser etéreo que cambiaba de forma según las imágenes que tuviera en mente quien la miraba" (p.124). Sobre este cuento, Cubillo ha señalado:

Lo ominoso de este relato radica en que claramente se borran los límites entre fantasía y realidad, pues algo que en un inicio no era más que la idea inicial para escribir un relato, cobra vida propia y afecta la vida cotidiana del escritor (sus amigos comenzaron a evitarlo y se quedó solo); pero además, sucede que un símbolo asume la plena operación y el significado de lo simbolizado. [...] Sin embargo, como ya indicamos, este episodio afecta de diversos modos la vida del escritor, al punto de que cuando la tía pobre finalmente abandona su espalda, él experimenta una fuerte crisis de identidad que le genera un sentimiento claramente ominoso (2011, p.25).

En diferentes análisis se ha abordado la búsqueda de la identidad propia, más auténtica, del personaje como causa del aparente desorden o alteración de sus acciones:

Ese miedo a la pérdida de la identidad también se ve reflejado en el cuento «El Espejo», en donde el narrador se espanta al tener conciencia de su propio 'yo' reflejado ante un espejo inexistente. Un «yo» completamente desconocido y alterado por la sociedad. Esta pérdida de la propia identidad y la 'automatización' de las personas a través de los medios, es el punto de shock y de terror en sus personajes, los cuales, continuamente piensan sobre quiénes son realmente y si el azar es quien en verdad dibuja sus personalidades (Echeverri, 2015, p.111).

En el relato La piedra con forma de riñón que se desplaza hay un doble juego de narración /metanarración en la trama; el marco de base del relato se atiene a las convenciones de la ficción 
realista: el protagonista, escritor, recuerda que, según su padre, en la vida de un hombre solo hay tres mujeres verdaderamente significativas; tras un primer fracaso, encuentra una mujer, misteriosa en lo que atañe a su profesión; se establece una relación entre ambos, y aquí se entrecruza la segunda línea argumental. Esa mujer, Kirie, le pide que le hable del relato que escribe y él, que antes era remiso a hacerlo, le explica que es una historia sobre una joven doctora que, en unas vacaciones en la montaña, ha encontrado una piedra con forma de riñón que se lleva a su despacho; la piedra cada día aparece en lugar distinto, y parece afectar a la joven que se va aislando, hasta que se deshace de ella en el mar; sin embargo, la piedra está de nuevo en su despacho al día siguiente. El escritor/ protagonista cree que la piedra está en la propia joven, que es parte de ella:

Esta piedra no debe de ser un objeto que proceda del exterior». Junpei llega a esta conclusión conforme va escribiendo el relato. El punto esencial es algo que se halla dentro de ella. Y ese algo de su interior está activando la piedra negra con forma de riñón. E impulsa a la doctora a hacer unas acciones concretas. Con este objetivo, envía señales sin cesar. Cambiando de sitio todas las noches (p.282).

Cuando él concluye de escribir el relato, no consigue contactar con Kirie, y se consuma así un caso más en que la mujer desaparece de la vida del personaje. Pero aquí además en un cruce o fusión metanarrativo:

Por la misma época, la piedra negra con forma de riñón desapareció de la mesa de la doctora. Una mañana, ella se dio cuenta de que la piedra ya no estaba allí. Ya no iba a volver jamás. Y, eso, ella ya lo sabía (p.286).

La desaparición de la mujer es recurrente en los relatos murakamianos; puede ir precedida de la desaparición del gato; así ocurre en Los gatos antropófagos. En La piedra con forma de riñón... desparece la mujer en el relato de base, y la piedra en la metanarración. En Tony Takitani la mujer fallece en accidente de tráfico. Las desapariciones y hechos misteriosos forman parte de la casuística narrativa de este autor, quien, según Sotelo, "se complace en el misterio que envuelve a 
los personajes, en el hecho de irlo descifrando a medida que se acumulan acontecimientos, sucesos extraños y estados cambiantes de la mente" (2013, p.315). Sotelo destaca, en efecto, los estados iniciales, los sucesos extraños y la fragilidad de los vínculos en las relaciones eróticas o de poder como los elementos narrativos básicos del autor; a los personajes, en estas coordenadas,

Les salva la magia de la vida, que a veces se explica por «la proyección del espíritu» y «las almas vegetativas», imágenes que aparecían a menudo en los relatos antiguos japoneses, donde el alma tenía vida propia y podía salir y entrar de los cuerpos en ciertos momentos (p.314).

Para encuadrar adecuadamente la génesis de su universo de fantasía, es imprescindible acudir a las explicaciones del profesor Rubio (2012, p.277), quien, desde su profundo conocimiento de la cultura japonesa, ha dejado bien asentada la poderosa tradición de la mitología fantástica japonesa en la obra de Murakami; para este especialista, en la obra de Murakami late inmutable el trasfondo ideológico de la cultura de su país, el universo tradicional japonés, perpetuado hasta el presente, que pauta aún hoy sus vidas de actos mágicos:

Los sucesos que configuran los argumentos de las novelas de Murakami, incluidos los relatos incrustados en las mismas, reproducen arquetipos orientales. Las desapariciones y las pérdidas que jalonan sus obras son hechos cuya naturaleza inexplicable, lejos de obsesionar o atormentar al personaje afectado como podría ocurrir con héroes occidentales, son vistas como hechos intrascendentes, como demostraciones tangibles de la porosidad de las paredes que en el edificio de la cultura japonesa separan realidad de irrealidad, como ilustraciones de un acontecer ajeno a la servidumbre de la causa y a la voluntad del agente (p.263).

Si hay dos relatos de carácter especialmente alejados de la lógica por la falta de congruencia entre los bloques textuales que los integran, se podría afirmar que se trata de Somorgujo y de La tragedia de la mina de carbón de Nueva York; en ambos casos, se yuxtaponen dos sorprendentes finales carentes de vinculación significativa con la historia más o menos convencional con la que el cuento 
se desarrolla hasta la abrupta conclusión, que no encaja desde la perspectiva del sentido lógico, sino que toma más bien la deriva del absurdo. El segundo de estos cuentos sabemos por el propio autor que es uno de los tres con los que arranca su dedicación al relato corto, a finales de los 70, cuando Murakami frisaba la treintena. No resultaría excesivo considerarlos, pues, por sus finales, muestra de narraciones del absurdo, de corte surrealista.

Con respecto a las conductas, acciones y reacciones de los personajes, es útil de nuevo a este tenor conocer cómo el escritor se ha posicionado:

No creo que las novelas con personajes planos, con un discurso sencillo y que hacen cosas previsibles despierten demasiado interés en los lectores. Para algunos las novelas lógicas con planteamientos lógicos quizá sean las mejores, pero a mí, personalmente, no me interesan nada. Más bien al contrario. Me parece fundamental que el personaje tenga la capacidad de hacer avanzar la historia, mucho más, sin duda, que el hecho de que resulte creíble o interesante (Murakami 2017, p.229).

El protagonista de El espejo, por ejemplo -quien empieza su relato declarándose poco dado a historias de espíritus o experiencias paranormales-, se desdobla en su otro yo ante un espejo, y esa figura le aterra. En un ambiente de terror, en medio de una noche espantosa, cree ver una figura, comprueba en el espejo que es él mismo, pero... diferente, lo mira con odio:

Lo único que comprendí entonces era que él me odiaba con todas sus fuerzas. Con un odio parecido a un poderoso iceberg que flota en un mar oscuro. Con un odio que no podrá ser jamás aliviado por nadie. Eso es lo único que comprendí (Murakami, 2008, p.56).

Como su propio reflejo parece querer dominarlo, aterrorizado rompe el espejo. Al día siguiente comprueba que no hubo tal espejo. Según Rubio (2012), el espejo se identifica con la divinidad en la literatura japonesa tradicional, actúa como la puerta espacio-temporal entre el mundo físico y el sobrenatural, una divisoria que si el protagonista traspasa, puede entrar en un territorio muy peligroso. Comprueba el protagonista su otro yo que jamás debía haber tomado forma. 
Sobre la presencia de símbolos, cabe decir que en algunos cuentos es indiscutible, por obvia. En Conitos el narrador protagonista decide retirarse de un concurso de pastelería dotado con un sustancioso premio cuando comprueba que unos desagradables enormes cuervos, los Cuervos Conitos, son decisivos para la elección del ganador; aquí el valor simbólico de los cuervos es tremendamente negativo, y remite al mundillo de la crítica de Japón, según confiesa el propio Murakami en el prólogo del libro: "Como pueden ver fácilmente los lectores, revela en forma de fábula mis impresiones del mundo literario cuando me publicaron por primera vez. En aquel momento no pude integrarme bien en el establishment literario japonés y esta situación persiste hoy día". Apoyar los eventos del relato con la entrada de elementos simbólicos resulta habitual en Murakami, y en el trasfondo cultural del que procede y en el bagaje ideológico inherente. Se ha puesto de relieve que

la presencia de símbolos, metáforas e imágenes en sus textos permite analizar la densidad de los mismos, ya que en muchas ocasiones los pensamientos e ideas de las personas ficcionales se expresan a través de ese método indirecto y sugerente. Esta técnica es típicamente japonesa, como si se quisieran decir las cosas sin decirlas (Sotelo, 2013, p.316).

Por otro lado, la técnica de emplear imágenes y metáforas con un contenido que rebasa la realidad sensorial se puede comprobar con facilidad a lo largo de los cuentos. Por ejemplo, en Los gatos antropófagos -cuento que Murakami explica después incorporararía, "con algunos cambios", a la novela Sputnik, mi amor- se describe la sensación del narrador protagonista al encontrarse en una isla griega, donde se ha marchado con la mujer que luego lo abandonaría; va más allá de la descripción geográfica, es de nuevo la percepción de otras realidades:

Aquel era, literalmente, el fin de Europa. Allí soplaba el viento del fin del mundo, se alzaban las olas del fin del mundo, flotaba el aroma del fin del mundo. Te gustara o no, así era el fin de un mundo. El lugar estaba teñido por los colores del inmovilismo y era imposible escapar de ellos. A mí me daba la sensación de estar siendo absorbido, en silencio, hacia el territorio de un cuerpo extraño. Una cosa ajena que se hallaba más allá del fin, vaga, extrañamente amable (p.105). 
Algún ejemplo similar de El cuchillo de caza: "La noche era profunda, y el tiempo, flexible y lleno a rebosar de savia. La luz de la luna llena acrecentaba sigilosamente esa hondura, esa flexibilidad" (p.91).

\section{Conclusión}

La revisión de los cuentos de Sauce ciego, mujer dormida permite comprobar el repertorio notable de contenidos y fórmulas que configuran la narrativa murakamiana. La dicotomía realismo / componente fantástico es, paradójicamente, clave en la fórmula del autor, quien atiende escrupulosamente a la realidad objetiva y observable, para desde ahí adentrarse en otra zona más simbólica y menos aprehensiva, que se conecta con su trasfondo personal de influencia japonesa, oriental. Los pasajes señalados de algunos cuentos muestran los aspectos reseñados, tanto en su modo fiel y ajustado de reflejar ambientes, sentimientos y circunstancias asociados a la realidad conocida, como también en otros en que se produce el giro hacia elementos fantásticos o simbólicos; en algún caso, se llega a la nota surrealista o del absurdo.

\section{Referencias}

Cubillo, R. (2011). Lo ominoso en el cuentario Sauce ciego, mujer dormida de Haruki Murakami. En Revista de Lenguas Modernas (15), 13-28.

Echeverri, A. (2015 Enero-junio). De qué hablo cuando hablo de Murakami. En Revista Mundo Asia Pacífico, 4(6), 100-114.

Murakami, H. (2008). Sauce ciego, mujer dormida. Barcelona. Tusquets. Traducción de Lourdes Porta Fuentes. Páginas citadas de la edición electrónica.

Murakami, H. (2017). De qué hablo cuando hablo de escribir. Barcelona: Tusquets. Traducción de Fernando Cordobés González y Yoko Ogihara.

Rubio, C. (2012). El Japón de Murakami. Madrid: Aguilar.

Sotelo, J. (2013). Los mundos de Murakami. Madrid: Izana Editores. 